\title{
A Review on Novel Designs for Microwave Power Transmission using Rectenna Array
}

\author{
Sree Lekshmi \\ Communication Systems \\ Electronics and Communication Engineering \\ TKM College of Engineering \\ Karicode, Kollam
}

\author{
Dr. Sheeba O \\ Professor \\ Electronics and Communication Engineering \\ TKM College of Engineering \\ Karicode, Kollam
}

\begin{abstract}
In this paper, a comparative study on different types of Rectenna array used for microwave power transfer (MPT) has been presented. Rectenna, which consist of an antenna combined with a rectifier, is an important part of microwave power transfer system. The antenna captures the microwave radiations from the atmosphere and these radiations are converted into a DC output value by the rectifying circuit. Thus, Rectenna converts the microwave radiations into useful electricity. Later, the output DC value from the rectifier will be able to charge portable low power electronic devices such as sensors, mobile, etc. Different antenna array configurations based on the shape of their patch, the number of patches, dielectric constant, etc have been compared. Various parameters such as the antenna type, frequency, rectifier type, maximum efficiency, gain, input power and the output voltage of different rectenna array types are analyzed and their performance is studied.
\end{abstract}

Keywords-Rectenna; antenna; rectifier; conversion efficiency; output voltage; Schottky diode.

\section{INTRODUCTION}

In today's world, electronic devices have become an important part of our life. But because of its power draining they need to be recharged frequently. And also we need to carry the chargers everywhere which is difficult. An optimized solution is using wireless energy harvesting systems where the ambient energy signals in the atmosphere can be used to produce the useful electricity. Microwave radiations are used for this purpose as they are not harmful to the humans and it can even penetrate through the ionosphere. Thus this system is safer and greener for the environment.

This objective is accomplished with the help of the technology of Microwave Power Transfer (MPT) system. The main component of MPT is RECTENNA (RECTtifying antENNA). It comprises of a rectifier preceded by an antenna as in the block diagram in Fig. 1. The antenna captures the microwave radiations from the atmosphere and these radiations are converted into a DC output value by the rectifying circuit. Thus, Rectenna converts the microwave radiations into useful electricity. Later, the output DC value from the rectifier will be able to charge portable low power electronic devices such as sensors, mobile, etc. Different antenna array configurations based on the shape of their patch, the number of patches, dielectric constant etc are available.

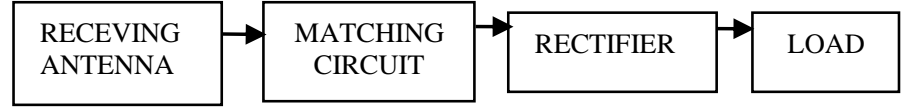

Fig 1: Block diagram of rectenna

A matching circuit is provided as the second block for the purpose of impedance matching and maximum power transfer. The last block of the rectenna is a load. By effectively adjusting the load resistance to a suitable value desired output voltage can be obtained. The antenna can be Microstrip Patch Antenna, Dipole antenna, Bipolar antenna, Array antenna, Planar antenna, Yagi-Uda antenna, Helical antenna, Parabolic antenna, etc. Rectifier can also be different types such as fullwave rectifier, voltage doubler, half-wave rectifier, etc. Depending upon the applications, antenna structure and rectifier type is selected.

\section{LITERATURE SURVEY}

Many researches have been done for rectenna array designs which use different kinds of rectenna array to improve its performance and efficiency. Table I shows different types of rectenna array designs and their performance which are compared in terms of the antenna type and rectifier element.

Tatsuki Matsunaga et al. [1] proposed a $5.8 \mathrm{GHz}$, stacked differential rectenna(Fig 2(a)) consisting of three microstrip patch antennas, two diodes, four shorted stubs, and two capacitors and it is extended to large scale rectenna array of 30 elements. The conversion efficiency achieved by this single rectenna is $44.1 \%$ when the received power density was as low as $0.041 \mathrm{~W} / \mathrm{m}^{2}$ as shown in Fig 2(b). Here, the received RF waves is applied to the rectifying diodes in antiphase i.e., differentially which effectively convert the RF power to DC.

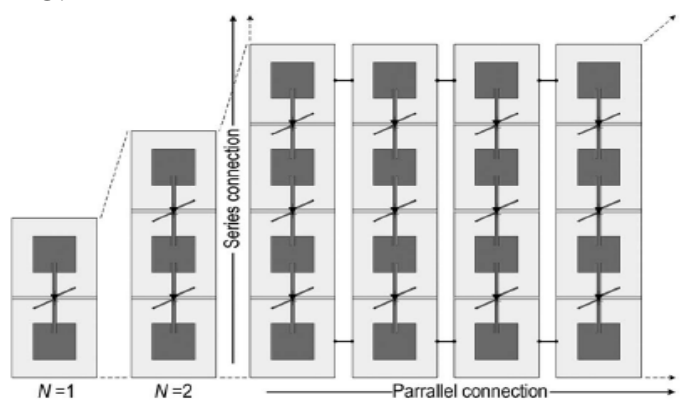

Fig 2(a): Proposed rectenna array 


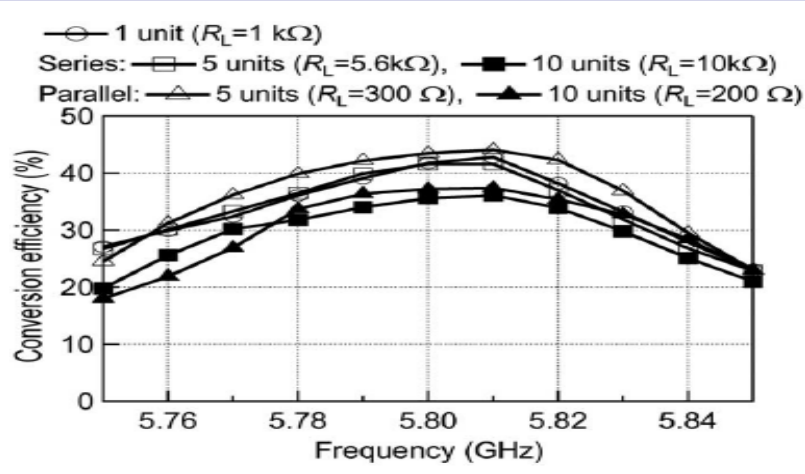

Fig 2(b): Measured conversion efficiency of 1-, 5-, and 10-unit rectennas.

Ali Mavaddat et al. [2] have developed a $35 \mathrm{GHz}$ energy harvester consisting of 16 elements of Microstrip patch antenna (Fig 3(a)) and a half-wave rectifier configuration. Between the antenna and the rectifier a step-impedance lowpass filter is used inorder to suppress the second-order harmonics generated by the diode in the rectifier circuit. The maximum RF-to-DC conversion efficiency achieved by this circuit is $67 \%$ with an input RF power of $7 \mathrm{~mW}$ as shown in Fig 3(b).

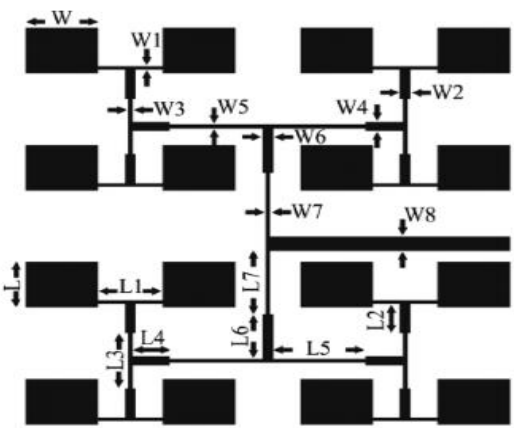

Fig 3(a): Developed Microstrip patch antenna array

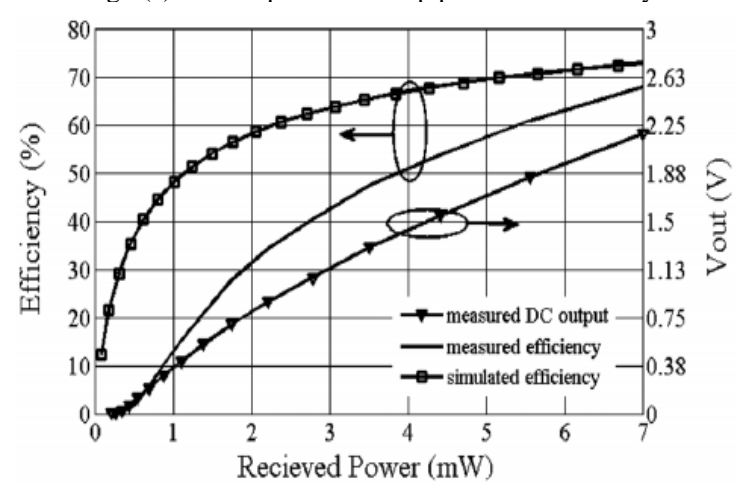

Fig 3(b): RF-to-DC power conversion efficiency of the rectenna array at $35 \mathrm{GHz}$

Hucheng Sun et al. [3] presents a new rectenna at $5.8 \mathrm{GHz}$ using beamwidth-enhanced antenna array of $1 \times 4$ square patch antenna. The beamwidth enhancement is achieved with optimal excitation distribution by maximizing the power transmission efficiency between the 4-element antenna array and two auxiliary antennas. The power conversion efficiency of rectenna array is higher than $50 \%$ when the power density is $1276 \mathrm{~mW} / \mathrm{cm}^{2}$.

Boris Kapilevich et al. [4] designed a W-band rectenna consisting of 4 rectangular patch antennas at $93 \mathrm{GHz}$ frequency. A low barrier MOTT diode is used as the rectifying diode which increases the conversion efficiency in comparison to other rectifying schemes using Schottky diodes. The measured conversion efficiency of this rectenna is $17.2 \%$.

Faruk Erkmen et al. [5] realized a $2.45 \mathrm{GHz}$ full-wave rectenna system which consists of two T-matched dipoles antennas connected to a full-wave rectifier. Schottky diodes of HSMS 286x family was used for rectification. The radiation-to-dc conversion efficiency obtained is $74 \%$ as shown in the Fig 4. Later it is extended to 18 elements in a $3 \times 6$ array configuration with an efficiency of $52 \%$.

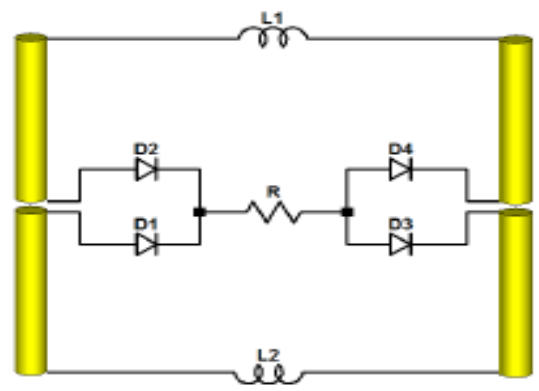

Fig 4(a): Proposed full-wave rectification system

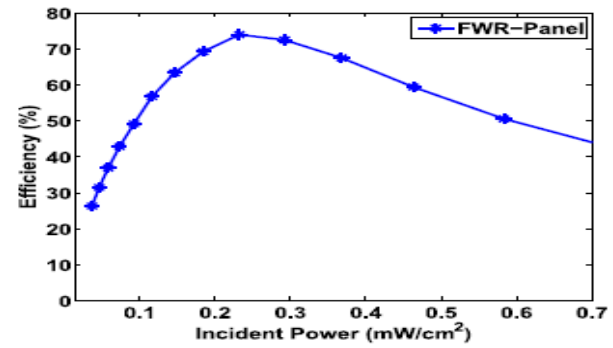

Fig 4(b): Radiation-to-dc conversion efficiency.

Salah-Eddine Adami et al. [6] proposed a flexible 2.45 $\mathrm{GHz}$ frequency rectenna of all-fabric patch antennas with proximity-coupled feed, rectifier on rigid substrate, broadside-coupled polarization lines between the antenna and the rectifier and a self-powered boost converter at the output as shown in Fig 5. This system is implemented as wrist band. Polyester felt and woven polyester are chosen as the substrates. The maximum end-to-end efficiency achieved by this system is $28.7 \%$ at $-7 \mathrm{dBm}$.

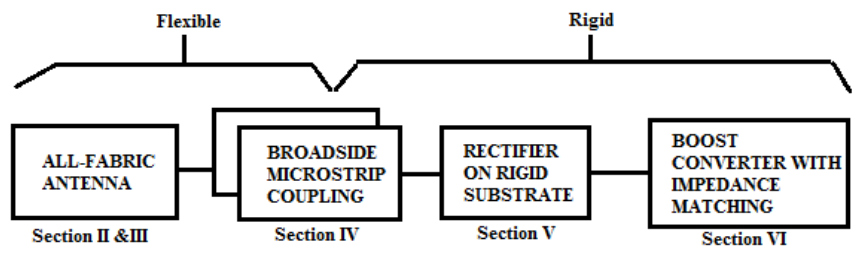

Fig 5: Block diagram of the flexible RF energy harvesting system

Yang Yang et al. [7] designed a $5.8 \mathrm{GHz}$ compact circularly-polarized rectenna with feedback wide-slot antenna $(5 \times 5)$ as shown in the Fig 6 . The rectifier uses HSMS 286C Schottky diodes in series which is integrated on the back side of the antenna substrate to minimize the size of the rectenna and Microstrip stubs are used for harmonic suppression. Maximum conversion efficiency of $62 \%$ and an output DC value of $26.81 \mathrm{~V}$ were obtained. 


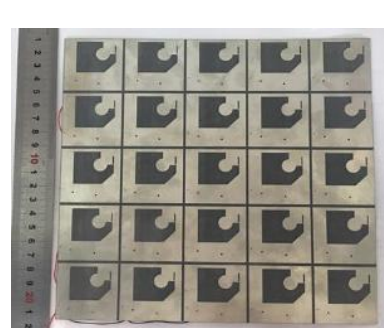

(a)

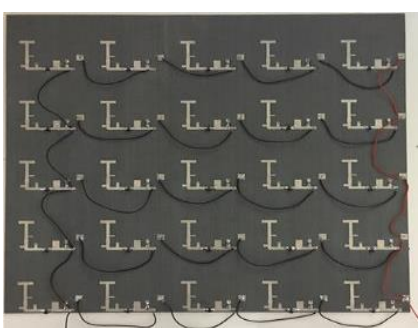

(b)
Fig 6: Rectenna array: (a) top view and (b) bottom view.

Yazhou Dong et al. [8] presented the first focused MPT system with circular polarization consisting of $8 \times 8$ square patch transmitting antenna array as shown in the Fig 7 and a high efficiency rectifying surface using sub-wavelength resonant elements. The highest RF-to-DC conversion efficiency of $66.5 \%$ was obtained.

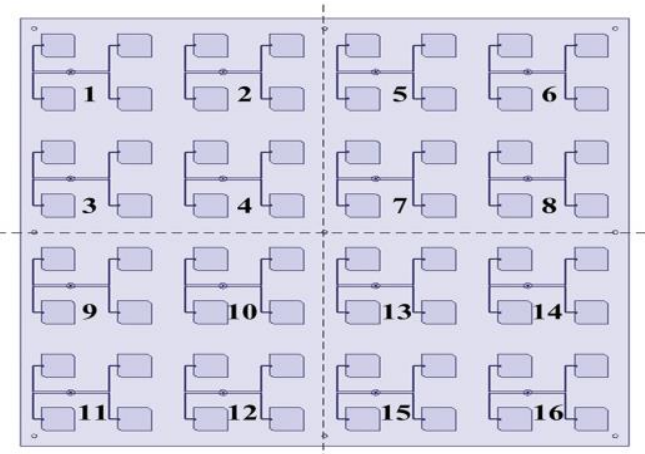

Fig 7: Transmitting antenna array

Dieff Vital et al. [9] presented a $2.45 \mathrm{GHz}$ fully-flexible, light weight and washable rectenna array for powering wearable sensors as shown in Fig 8. Textile-based antennas onto fabric-based substrates and single-diode based rectifier circuit were developed. A $2 \times 3$ array was then fabricated and tested. An RF-to-DC conversion efficiency of $70 \%$ at $8 \mathrm{dBm}$ and gain of $5.2 \mathrm{dBi}$ was obtained.
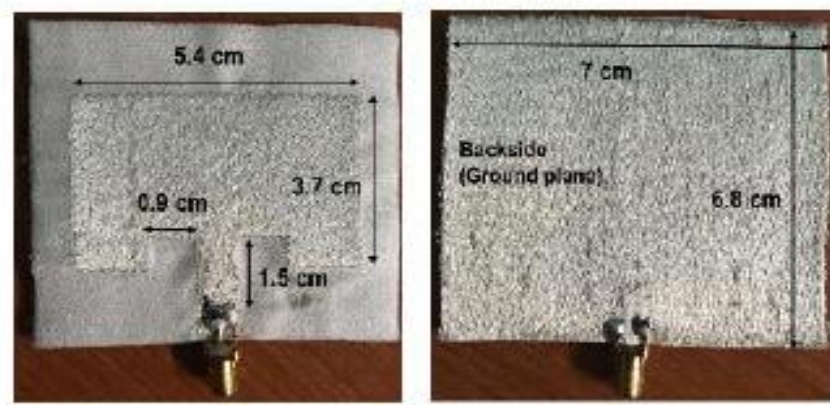

Fig 8: Textile-based antenna

$\mathrm{Xi} \mathrm{Li}$ et al. [10] designed a $2.45 \mathrm{GHz}$ frequency lowprofile air supported Microstrip antenna to reduce substrate losses as shown in Fig 9. To adapt various power densities, two-element series-fed array and four-element cascaded array were designed. The diode used in the rectifier is HSMS-282C in series and a maximum RF-to-DC conversion efficiency of $80 \%$ achieved at $21 \mathrm{dBm}$ input power. The maximum efficiency of rectenna obtained was $77.2 \%$ and output DC voltage was $18.5 \mathrm{~V}$.

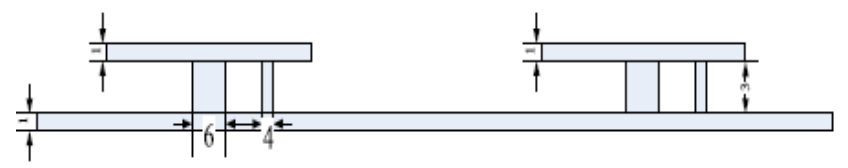

Fig 9: Side view of antenna element

TABLE I: COMPARISON OF DIFFERENT RECTENNA ARRAY CONFIGURATIONS AND THEIR PERFORMANCES

\begin{tabular}{|c|c|c|c|c|c|}
\hline Ref. & Year & Frequency & Antenna type & Rectifier element & Remarks \\
\hline [1] & 2015 & $5.8 \mathrm{GHz}$ & $\begin{array}{l}\text { Microstrip patch antenna } \\
\text { array }(30 \text { element })\end{array}$ & $\begin{array}{l}\text { MSS-20145-B10D Schottky } \\
\text { diodes }\end{array}$ & $\begin{array}{l}\begin{array}{l}\text { Effectively convert } \\
\text { differential operation. }\end{array} \\
\text { difor to DC using } \\
\end{array}$ \\
\hline [2] & 2015 & $35 \mathrm{GHz}$ & $\begin{array}{l}\text { Microstrip patch antenna } \\
\text { array, } 4 \times 4\end{array}$ & $\begin{array}{l}\text { GaAs Schottky diode } \\
\text { MA4E1317 }\end{array}$ & Suited for millimeter-wave energy harvesting. \\
\hline [3] & 2016 & $5.8 \mathrm{GHz}$ & $\begin{array}{l}\text { Square patch antenna array, } \\
\qquad 1 \times 4 \\
\end{array}$ & $\begin{array}{l}\text { HSMS-2860 Schottky } \\
\text { diode }\end{array}$ & Much wider beamwidth at the H-plane. \\
\hline [4] & 2016 & $93 \mathrm{GHz}$ & $\begin{array}{l}\text { Rectangular patch antenna } \\
\text { array, } 2 \times 2\end{array}$ & Low barrier Mott diode & $\begin{array}{l}\text { Improved conversion efficiency than } \\
\text { conventional rectennas using Schottky diodes. }\end{array}$ \\
\hline [5] & 2017 & $2.45 \mathrm{GHz}$ & $\begin{array}{l}\text { T-matched dipole antenna } \\
(3 \times 6)\end{array}$ & $\begin{array}{l}\text { HSMS-2863, HSMS- } \\
2864 \\
\end{array}$ & Better efficiency than half-wave rectennas. \\
\hline [6] & 2018 & $2.45 \mathrm{GHz}$ & All-fabric patch antenna & $\begin{array}{l}\text { SMS7630 Schottky } \\
\text { diode }\end{array}$ & $\begin{array}{l}\text { Flexible, wearable, wideband and efficient } \\
\text { system. }\end{array}$ \\
\hline [7] & 2018 & $5.8 \mathrm{GHz}$ & Wide slot antenna, $5 \times 5$ & $\begin{array}{l}\text { HSMS-2826C (2) in } \\
\text { series }\end{array}$ & $\begin{array}{l}\text { Simple, easy to integrate and low sidelobes. } \\
\text { Conversion efficiency of array is lower than } \\
\text { single rectenna. }\end{array}$ \\
\hline [8] & 2018 & $5.8 \mathrm{GHz}$ & $\begin{array}{l}\text { Square patch antenna array, } \\
\qquad 8 \times 8\end{array}$ & MA4E1317 diode & $\begin{array}{l}\text { Output power and efficiency increased due to } \\
\text { focused and high efficiency rectifying surface. }\end{array}$ \\
\hline [9] & 2019 & $2.45 \mathrm{GHz}$ & $\begin{array}{l}\text { Rectangular patch antenna } \\
\text { array, } 2 \times 3\end{array}$ & SMS7630 & Low-cost, low loss, flexible, light weight. \\
\hline [10] & 2019 & $2.45 \mathrm{GHz}$ & $\begin{array}{l}\text { Rectangular patch antenna } \\
\text { array, } 2 \times 2\end{array}$ & $\begin{array}{l}\text { HSMS-282C (2) in } \\
\text { series }\end{array}$ & $\begin{array}{l}\text { Air as substrate and can adapt to various } \\
\text { power densities to improve efficiency. }\end{array}$ \\
\hline
\end{tabular}




\section{RESULT COMPARISON OF DIFFERENT RECTENNA ARRAY CONFIGURATIONS}

Table II describes the result comparison of different rectenna array configurations based on antenna gain, input power, maximum efficiency and output voltage. The "NA" indicates that not available information in the reviewed papers.

TABLE II: COMPARISON RESULTS OF DIFFERENT RECTENNA ARRAY CONFIGURATIONS

\begin{tabular}{|c|l|c|l|l|c|}
\hline Ref. no. & Frequency & Antenna gain & Input Power & $\begin{array}{c}\text { Maximum } \\
\text { Efficiency }\end{array}$ & $\begin{array}{c}\text { Output DC } \\
\text { Voltage }\end{array}$ \\
\hline$[1]$ & $5.8 \mathrm{GHz}$ & $\mathrm{NA}$ & $0.041 \mathrm{~W} / \mathrm{cm}^{2}$ & $44.1 \%$ & $4 \mathrm{~V}$ \\
\hline$[2]$ & $35 \mathrm{GHz}$ & $19 \mathrm{dBi}$ & $7 \mathrm{~mW}$ & $67 \%$ & $2.18 \mathrm{~V}$ \\
\hline$[3]$ & $5.8 \mathrm{GHz}$ & $\mathrm{NA}$ & $15.2 \mathrm{dBm}$ & $17.2 \%$ & $\sim 3 \mathrm{~V}$ \\
\hline$[4]$ & $93 \mathrm{GHz}$ & $18 \mathrm{dBi}$ & $\mathrm{NA}$ & $52 \%$ & $\sim 1 \mathrm{~V}$ \\
\hline$[5]$ & $2.45 \mathrm{GHz}$ & $\mathrm{NA}$ & $0.14 \mathrm{~mW} / \mathrm{cm}^{2}$ & $\mathrm{NA}$ \\
\hline$[6]$ & $2.45 \mathrm{GHz}$ & $8.1 \mathrm{dBi}$ & $-7 \mathrm{dBm}$ & $62 \%$ & $3 \mathrm{~V}$ \\
\hline$[7]$ & $5.8 \mathrm{GHz}$ & $6.4 \mathrm{Db}$ & $12.2 \mathrm{~mW} / \mathrm{cm}^{2}$ & $66.5 \%$ & $26.81 \mathrm{~V}$ \\
\hline$[8]$ & $5.8 \mathrm{GHz}$ & $\mathrm{NA}$ & $11 \mathrm{~mW} / \mathrm{cm}^{2}$ & $70 \%$ & $2.8 \mathrm{~V}$ \\
\hline$[9]$ & $2.45 \mathrm{GHz}$ & $5.2 \mathrm{dBi}$ & $8 \mathrm{dBm}$ & $80 \%$ & $\mathrm{NA}$ \\
\hline$[10]$ & $2.45 \mathrm{GHz}$ & $8.8 \mathrm{dBi}, 11.5 \mathrm{dBi}, 13.4 \mathrm{dBi}$ & $21 \mathrm{dBm}$ & & $18.5 \mathrm{~V}$ \\
\hline
\end{tabular}

* "NA" indicates not available information in the reviewed papers.

\section{CONCLUSION}

This paper compared different rectenna array configurations and their performance is evaluated based on various parameters such as gain, conversion efficiency, output voltage, etc. The performance of these parameters can be improved by optimization done in the antenna size, suppressing harmonic frequencies, etc.

\section{REFERENCES}

[1] T. Matsunaga, E. Nishiyama, and I. Toyoda, "5.8-GHz stacked differential rectenna suitable for large-scale rectenna arrays with $\mathrm{dc}$ connection," IEEE Trans. Antennas Propag., vol. 63, no. 12, pp. 5944 5949,Dec. 2015.

[2] T. Matsunaga, E. Nishiyama, and I. Toyoda, "5.8-GHz stacked differential rectenna suitable for large-scale rectenna arrays with dc connection,” IEEE Trans. Antennas Propag., vol. 63, no. 12, pp. 5944 5949,Dec. 2015.

[3] Hucheng Sun and Wen Geyi, "A New Rectenna Using BeamwidthEnhanced Antenna Array for RF Power Harvesting Applications", IEEE Antennas and Wireless Propagation Letters, vol. 16, pp. 14511454, 2016.

[4] Boris Kapilevich, Vladimir Shashkin, Boris Litvak, Gil Yemini, Ariel Etinger, Danny Hardon, and Yosef Pinhasi, "W-Band Rectenna Coupled With Low-Barrier Mott Diode", IEEE Microwave and Wireless Components Letters, vol. 26, no. 8, pp. 637-639, August 2016.
[5] Faruk Erkmen, Thamer S. Almoneef and Omar M. Ramahi, "Electromagnetic Energy Harvesting Using Full-Wave Rectification", IEEE Transactions on Microwave Theory and Techniques, vol. 65,no. 5, pp. 1843-1851, May 2017.

[6] Salah-Eddine Adami, Plamen Proynov, Geoffrey S. Hilton, Guang Yang, Chunhong Zhang, Dibin Zhu, Yi Li, Steve P. Beeby, Ian J. Craddock and Bernard H. Stark, "A Flexible 2.45-GHz Power Harvesting Wristband With Net System Output From -24.3 dBm of RF Power", IEEETtransactions on Microwave Theory and Techniques, vol.66, no. 1, pp. 380-395, Jan. 2018.

[7] Yang Yang, Jun Li, Lu Li, Yilin Liu, Bing Zhang, Huacheng Zhu and Kama Huang, "A $5.8 \mathrm{GHz}$ Circularly Polarized Rectenna with Harmonic Suppression and Rectenna Array for Wireless Power Transfer", IEEE Antennas and Wireless Propagation Letters, vol.17, no. 7, pp.1276-1280, July 2018.

[8] Yazhou Dong, Shi-Wei Dong, Ying Wang, Shuo Liu, Xiaojun Li, Steven Gao, Gao Wei, Lixin Ran, "Focused microwave power transmission system with high-efficiency rectifying surface", IET Microwaves, Antennas \& Propagation, vol. 12, no. 5, pp. 808-813, April 2018.

[9] Dieff Vital, Shubhendu Bhardwaj, John L. Volakis, “A 2.45 GHz RF Power Harvesting System Using Textile-Based Single-Diode Rectennas", IEEE/MTT-S International Microwave Symposium, pp. 1313-1315, Aug. 2019.

[10] Xi Li, Lin Yang, Li Huang, "Novel Design of 2.45-GHz Rectenna Element and Array for Wireless Power Transmission", IEEE Access, vol. 7, pp. 2169-3536, March 2019. 